\title{
SARCOPENIA, BONE MINERAL DENSITY, AND VITAMIN D: EPIFLORIPA AGING STUDY 2013/2O14
}

\section{Sarcopenia, densidade mineral óssea e vitamina $\mathrm{D}$ : Estudo EpiFloripa Idoso 2013/2014}

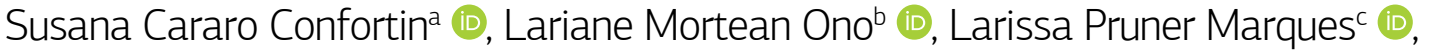

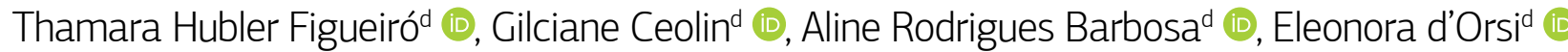

OBJECTIVE: To verify associations between osteopenia/osteoporosis and vitamin D and sarcopenia in the older adult population of Florianópolis, Brazil. METHODS: A cross-sectional population-based study, with 604 older adults (60 years and over). The appendicular muscle mass index (AMMI) was used to identify sarcopenia, with cutoffs of AMMl $\left(\mathrm{Kg} / \mathrm{m}^{2}\right)<7.26 \mathrm{~kg} / \mathrm{m}^{2}$ for men and $<5.50 \mathrm{~kg} / \mathrm{m}^{2}$ for women indicating inadequate values (sarcopenia). The independent variable osteopenia/osteoporosis was measured using bone mineral density $\left(B M D, g / \mathrm{cm}^{2}\right)$ : T-Scores for whole body BMD, lumbar spine BMD, and femoral neck BMD, categorized as normal (BMD $\geq-1 \mathrm{SD}$ ) or osteopenia/osteoporosis (BMD $<-1$ SD from the mean of the young adult reference population). Fasting serum samples were collected and assayed using the microparticle chemiluminescence (CMIA)/Liaison method. Vitamin D concentrations of $<30 \mathrm{ng} / \mathrm{mL}$ were defined as hypovitaminosis. Crude and adjusted logistic regression analyses were performed. RESULTS: Osteopenia/osteoporosis in the lumbar spine and femoral neck were associated with higher odds of sarcopenia in women and men. Osteopenia/osteoporosis in the whole body was associated with sarcopenia in women only. Vitamin D was not associated with sarcopenia in either sex. CONCLUSIONS: Having osteopenia/osteoporosis was associated with sarcopenia in this older adult population.

KEYWORDS: sarcopenia; osteoporosis; bone diseases, metabolic; aged.

OBJETIVO: Verificar a associação entre osteopenia/osteoporose e vitamina D com a sarcopenia na população idosa de Florianópolis. METODOLOGIA: Estudo transversal de base populacional, com 604 idosos (60 anos ou mais). 0 índice de massa muscular apendicular (IMMA) foi utilizado para identificar a sarcopenia, onde o IMMA $\left(\mathrm{Kg} / \mathrm{m}^{2}\right)-<7,26 \mathrm{~kg} / \mathrm{m}^{2} \mathrm{para}$ homens e $<5,50 \mathrm{~kg} / \mathrm{m}^{2}$ para mulheres — indicava valores inadequados (sarcopenia). A variável independente osteopenia/ osteoporose foi medida pela densidade mineral óssea (DMO, $\left.\mathrm{g} / \mathrm{cm}^{2}\right)$, foram calculados os T-escores para DMO corporal total, DMO da coluna lombar e DMO do colo femoral, categorizados como normais (DMO até -1 DP) ou osteopenia/osteoporose (DMO < -1 DP da média da população adulta jovem de referência). Amostras de soro em jejum foram coletadas pelo método de quimioluminescência de micropartículas (CMIA)/Liaison. Concentrações de vitamina $\mathrm{D}<30 \mathrm{ng} / \mathrm{mL}$ foram definidas como hipovitaminose. Foi realizada análise de regressão logística bruta e ajustada. RESULTADOS: Osteopenia/osteoporose na coluna lombar e colo do fêmur foram associadas a maiores chances de sarcopenia em mulheres e homens. Osteopenia/ osteoporose no corpo total foi associada à sarcopenia apenas em mulheres. A vitamina D não foi associada à sarcopenia em ambos os sexos. CONCLUSÕES: A presença de osteopenia/osteoporose associou-se à sarcopenia nesta população de idosos. PALAVRAS-CHAVE: sarcopenia; osteoporose; doenças ósseas metabólicas; idoso.

aUniversidade Federal do Maranhão - São Luís (MA), Brazil.

Universidade Federal do Paraná - Curitiba (PR), Brazil.

'Escola Nacional de Saúde Pública Sergio Arouca, Fundação Oswaldo Cruz - Rio de Janeiro (RJ), Brazil.

dUniversidade Federal de Santa Catarina - Florianópolis (SC), Brazil.

Correspondence data

Susana Cararo Confortin - Rua Marcelino Champagnat, 20 - Jardim Renascença - CEP: 65075-045 - São Luís (MA), Brazil. E-mail: susanaconfortin@gmail.com Received on: 06/26/2020. Accepted on: 10/23/2020

https://doi.org/10.5327/Z2447-212320202000079 


\section{INTRODUCTION}

Changes in body composition related to advancing age are well documented in the literature. ${ }^{1,2}$ The decline in muscle mass between the ages of 40 and 80 years has been estimated at 30 to $60 \%$, respectively. ${ }^{3}$ In comparison, bone mass deteriorates gradually, with onset at middle age, at a rate of approximately $1 \%$ per year. ${ }^{4}$

The geriatric syndrome characterized by progressive loss of mass and muscular strength is called sarcopenia. ${ }^{5}$ Loss and deterioration of bone mass is known as osteoporosis and is considered a multifactorial disease. ${ }^{6}$ Both diseases are common and have negative impacts on the health of older adults, leading to inability to perform activities of daily living, worsening of quality of life, risk of fragility fracture, increased risk of falls, and mortality. ${ }^{7-9}$

Sarcopenia and osteoporosis appear to be related ${ }^{8,10}$ and have several aspects in common, ranging from more frequent incidence in women and prevalence that increases with age, to their complications, impact on health, and social repercussions. ${ }^{8}$ Previous studies have shown that physical activity, testosterone levels, estrogen, growth hormone, interleukin-6, and vitamin $\mathrm{D}^{8,10}$ are all factors associated with both sarcopenia and bone mineral density (BMD). The importance of vitamin $\mathrm{D}$ to bone density is well established. However, in relation to sarcopenia, a growing body of literature suggests a possible mechanism of action through interaction with the vitamin D receptor (VDR) present in muscle cells, showing that related studies are required. ${ }^{10}$

There are other factors also related to development of sarcopenia, such as behavioral habits, disabling injuries, and biochemical and physiological changes. ${ }^{11}$ Similarly, loss of bone mass depends on behavioral and environmental factors and complex mechanisms that lead to greater risk of fragility fracture in older adults. ${ }^{4}$ These conditions impose high cost burdens for healthcare and social support. ${ }^{12}$ Data for the year 2000 from the United States estimated expenditure on sarcopenia of approximately US\$18.5 billion in older adults, which equated to $1.50 \%$ of health expenditure that year. ${ }^{13}$ The economic impact of sarcopenia may be comparable to that attributed to osteoporosis. ${ }^{14}$ In the Brazilian Unified Health System, 3252756 procedures related to the treatment of osteoporosis were performed between 2008 and 2010, with a total cost of almost US\$ 53 million. ${ }^{12}$

Data indicate that there is a relationship between loss of muscle mass and bone mass, ${ }^{11,15}$ such that osteoporosis could be a predictor of sarcopenia., ${ }^{3,8,16}$ Thus, assessment of osteoporosis would be one of the indicators for screening of individuals with sarcopenia.

Although sarcopenia is related to and has the same adverse health effects as osteopenia/osteoporosis, ${ }^{8,9}$ it is seldom or rarely assessed by health professionals. The strategy of screening for sarcopenia through osteoporosis is intended to achieve diagnosis, accelerate treatment and direct interventions, and avoid further complications, enabling older adults to preserve autonomy and independence for longer.

Healthy aging is determined by older adults' autonomy and independence and is only achieved through integration between muscles, joints, and bones. ${ }^{4}$ Study of the relationships between these elements is essential for development of intervention strategies ${ }^{17}$ aimed at maintaining muscle and bone mass. Therefore, the objective of the present study was to verify associations between osteopenia/osteoporosis and vitamin $\mathrm{D}$ and sarcopenia in older adult residents in the city of Florianópolis, Santa Catarina (SC), Brazil.

\section{METHODS}

This cross-sectional study was carried out with information from the second wave of the survey entitled Conditions of the health of the older adults in Florianópolis - EpiFloripa Aging Study. The baseline study was conducted in 2009/2010 and the follow-up in 2013/2014. The EpiFloripa Aging Study is a population-based, household-based, longitudinal study that evaluates older adult individuals of both sexes aged 60 years and older living in the urban area of Florianópolis, Santa Catarina, Brazil.

A prior publication ${ }^{18}$ has described the population and study sample in greater detail. Briefly, the sample calculation indicated the need for at least 1599 interviews (2009/2010) to represent the city's older adult population. The sample was selected in two stages: first, the urban census tracts of the city were systematically drawn and stratified in ascending order of the average monthly income of the head of the family; the second stage was selection of households in these sectors, which were also systematically drawn.

Data from the present study come from the second wave of the EpiFloripa Aging Study. Data were collected during faceto-face structured interviews (November 2013 to November 2014) and by imaging exams, laboratory tests, and physical-functional capacity tests conducted at the Universidade Federal de Santa Catarina (March 2013 to March 2014).

The baseline sample (2009/2010) comprised 1702 older adults. Of these, 505 were lost to the sample. There were 217 deaths, 159 could not be located, and 129 refused to participate. The sample for the home visit stage of the second wave comprised 1197 older adults (80.60\%), and 604 (50.40\%) of these participated in laboratory tests,imaging exams, and physical-functional capacity tests. The analytical sample of this study comprised 598 older adults after six were excluded because the information from their imaging exams was incomplete. 


\section{Dependent variable}

Sarcopenia was identified from muscle mass analysis using a Dual Energy X-ray Absorptiometry (DXA) dual-density densitometer (Lunar Prodigy Advance Model, General Electric). The appendicular muscle mass index (AMMI) (lean muscle mass of the arms $[\mathrm{kg}]+$ lean muscle mass of the legs $[\mathrm{kg}] /$ height $^{2}[\mathrm{~m}]$ ) was used to evaluate sarcopenia with cutoffs of $\leq 2$ standard deviations (SD) in relation to the mean according to sex for the young adult population in the Rosetta Study ${ }^{7}$ used to classify participants as positive for this condition. Thus, AMMI $\left(\mathrm{kg} / \mathrm{m}^{2}\right)<7.26 \mathrm{~kg} / \mathrm{m}^{2}$ for men and $<5.50 \mathrm{~kg} / \mathrm{m}^{2}$ for women were defined as greater than normal loss of muscle mass and classified as sarcopenia.

\section{Independent variables}

Osteopenia was grouped with osteoporosis and classified by means of bone mineral density $\left(\mathrm{BMD}, \mathrm{g} / \mathrm{cm}^{2}\right)$, measured using DXA. T-Scores ${ }^{19}$ (calculated using the SD for mean BMD at peak bone mass in young adults) were calculated for T-score whole body BMD, lumbar spine BMD, and femoral neck BMD. We defined values as normal if they were no less than $-1 \mathrm{SD}$ of the mean from the reference population of young adults of the same sex from the EpiFloripa Adult Study. Osteopenia/osteoporosis was defined as present for each measure when BMD $<-1 \mathrm{SD}^{20}$ of the mean from the reference population of young adults of the same sex from the EpiFloripa Adult Study. Presence of osteopenia/osteoporosis was analyzed individually for each measure performed.

Vitamin D (Vitamin D 25 Hydroxy or 25-OH Vitamin D) - Fasting serum samples were collected and frozen in a freezer at $-80^{\circ} \mathrm{C}$. Vitamin $\mathrm{D}$ was measured between November 2016 and April 2017 using the microparticle chemiluminescence (CMIA)/Liaison method. Concentrations of vitamin $\mathrm{D}$ between 30 and $100 \mathrm{ng} / \mathrm{mL}$ were considered normal, whereas values $<30 \mathrm{ng} / \mathrm{mL}$ were defined as hypovitaminosis (which combines the cutoff points for insufficiency and deficiency), according to the recommendations for older adult populations of the Brazilian Society of Endocrinology and Metabolism (Sociedade Brasileira de Endocrinologia e Metabologia [SBEM] $),{ }^{21}$ Because vitamin D concentration is partially dependent on exposure to sunlight, higher serum levels are identified in the spring and summer, necessitating adjustment of the model for the season of the year in which the blood sample was collected, to minimize seasonal effects. ${ }^{21}$

\section{Adjustment variables}

Based on data in the literature, ${ }^{7,16}$ the following adjustment variables were used: age (continuous), schooling measured in years of study (no formal study; 1 to $4 ; 5$ to
8; 9 to 11 ; or $\geq 12$ years), smoking (never smoked; former smoker, quit; or currently smoking), ingestion of alcoholic beverages (not consuming; non-abusive consumption; or abusive consumption), physical activity in leisure and displacement ${ }^{22}$ (insufficiently active [ $<150$ minutes of physical activity in leisure and weekly displacement] or physically active [ $\geq 150$ minutes of leisure-time physical activity and weekly displacement]), fall last year (yes or no) and dependency for activities of daily living (ADL) 23 (no [dependence or dependence for up to 3 activities] or yes (dependence for 4 or more activities]).

\section{Data analysis}

For all analyses, we used sample weightings, which consider the effect of the cluster sampling design. All variables were expressed as proportions and $95 \%$ confidence intervals (95\%CI). Likewise, prevalence and $95 \% \mathrm{CI}$ of sarcopenia were described for each sex according to independent variables.

Logistic regression was used to investigate associations, estimating the Odds Ratio (OR) and its respective $95 \% \mathrm{CI}$ in crude and adjusted analyses. Three adjustment models were esimated for the associations between each osteopenia/osteoporosis variable and sarcopenia:

- Model 1) Adjusted for age and schooling;

- Model 2) Adjusted for age; schooling; smoking; alcohol consumption; physical activity; falls; and ADL dependency;

- Model 3) Adjusted for age; schooling; smoking; alcohol consumption; physical activity; falls; ADL dependency; vitamin D level; and season.

For the association between Vitamin D and sarcopenia, the following models were estimated:

- Model 1) Adjusted for age; schooling; and season;

- Model 2) Adjusted for age; schooling; smoking; alcohol consumption; physical activity; falls; ADL dependency; and season;

- Model 3) Adjusted for age; schooling; smoking; alcohol consumption; physical activity; falls; ADL dependency; season; T-score whole body, T-score BMD lumbar spine; and T-score BMD femoral neck.

The statistical program Stata / SE 13.0 (Stata Corp., College Station, USA) was used to perform the analyses.

\section{Ethical considerations}

The Human Research Ethics Committee at the Universidade Federal de Santa Catarina approved the project (CAAE no 16731313.0.0000.0121). The interviewees all signed a free and informed consent form. 


\section{RESULTS}

The sample comprised 598 subjects (aged from 63 to 93 years), 391 (65.41\%) of whom were women. Mean age was $72.46( \pm 6.24)$ years for women and $72.00( \pm 6.35)$ years for men. The proportions of women and men who had sarcopenia were $17.03 \%$ (95\%CI 12.40 - 22.87) and 28.81\% (95\%CI 21.35 - 37.67) respectively.

Table 1 shows the characteristics of the sample by sex. There were more women than men and the most prevalent categories among women were 1 to 4 years of study, no alcohol consumption, never smoked, physically active, no functional dependence, and no history of falls in the previous year. In relation to bone density variables, a majority of women did have osteopenia/osteoporosis in the whole body, in the lumbar spine, and the neck of the femur, and a majority did have hypovitaminosis D. Among men, the most prevalent categories were 12 years or more of study, alcohol abuse, ex-smokers, physically active, without functional dependence, and no history of falls in the previous year. In relation to bone density variables, a majority of men did not have osteopenia/osteoporosis in the whole body or lumbar spine, but did have osteopenia/osteoporosis in the femoral neck and did have hypovitaminosis D.

The results of the analyses of associations between sarcopenia and the osteopenia/osteoporosis variables for women and men are presented in Tables 2 and 3, respectively. For women, all osteopenia/osteoporosis variables were associated with sarcopenia, even after adjustments in models 1,2 , and 3. For men, all osteopenia/osteoporosis variables were associated with sarcopenia in the crude analysis, except for osteopenia/osteoporosis in the whole body. Vitamin D was not associated with sarcopenia in the crude analysis for either sex. Despite this non-association, it was nevertheless decided to adjust the analysis between vitamin $\mathrm{D}$ and sarcopenia to verify the results. However, vitamin $\mathrm{D}$ was not associated with sarcopenia in any of the adjusted models.

\section{DISCUSSION}

The results showed osteopenia/osteoporosis in the lumbar spine and femoral neck was positively associated with sarcopenia in both sexes. However, osteopenia/osteoporosis in the whole body was only associated with sarcopenia in women. Additionally, we did not find any association in the models adjusted by vitamin $\mathrm{D}$.

Osteopenia/osteoporosis in the lumbar spine and femoral neck was associated with sarcopenia in both sexes. Several potential mechanisms for sarcopenia, as well as the relationship between sarcopenia and osteopenia/osteoporosis, have been investigated..$^{10,16,17}$ However, sarcopenia was treated as an independent variable in most studies. ${ }^{20,24} \mathrm{Few}$ studies have been conducted with sarcopenia as an outcome, as in the present study. Yoshimura et al. ${ }^{16}$ showed mutual associations between sarcopenia and osteoporosis in the lumbar spine and/or the femoral neck, in a cross-sectional analysis. Even after adjusting for confounding variables, presence of osteoporosis remained associated with sarcopenia $(\mathrm{OR}=2.86 ; 95 \% \mathrm{CI} 1.59-5.13)$. Furthermore, these authors found results in a longitudinal analysis (4 years),in which osteoporosis was a predictor of sarcopenia. However, they did not present an explanation for this relationship or propose hypotheses for the association found. ${ }^{16}$

Some possible hypotheses were reviewed in a recent study indicating that there is a relatively new concept in which the bone functions as an endocrine organ with some derivative factors that can affect the muscle such as osteocalcin, sclerostin, prostaglandin $\mathrm{E} 2$, protein-dentin matrix 1, endopeptidases on the $\mathrm{X}$ chromosome, and TGF- $\beta$, among others. ${ }^{15}$

In two other studies in which sarcopenia was the outcome, there were no associations between sarcopenia and osteopenia/osteoporosis. In a study by Pongchaiyakul et al., ${ }^{25}$ there was no association between osteopenia/osteoporosis (femoral neck) and sarcopenia for men or women (20-84 years) from Bangkok, Thailand. Figueiredo et al. ${ }^{26}$ investigated older men from the city of São Paulo, SP, Brazil, and also found no associations between lower bone mineral density parameters (lumbar spine BMD and femoral neck BMD) and sarcopenia.

The findings of the present study point to the existence of a bidirectional relationship between muscle and bone tissues, extending the link beyond the purely mechanical perspective, ${ }^{27}$ as is explored in most scientific articles. It is precisely the existence of physical, genetic, and molecular connections that make study of the different mechanisms of interaction between these types of tissues complex. ${ }^{10}$

A recent study showed that cells present in the bone marrow, such as osteocytes, are capable of releasing substances and factors that stimulate proliferation of muscle cells, in addition to regulating osteogenesis and reabsorption of bone tissues. ${ }^{10}$ This may be a possible explanation for the results observed in the present study, providing a new perspective on the relationship between osteopenia/osteoporosis and sarcopenia. The magnitude of associations between exposures (osteopenia/osteoporosis in the lumbar spine and femoral neck) and outcome (sarcopenia) was high, especially in women.

Assessment and identification of sarcopenia are not routine examinations in primary care, whereas bone densitometry is more widely used and diffused in clinical practice. Thus, these results and possible changes may provide important information for screening of older adults, who are prone to developing sarcopenia. 
Table 1. Description of the sample and prevalence of sarcopenia according to demographic, socioeconomic, lifestyle, and health status variables, and osteopenia/osteoporosis in older adults.

\begin{tabular}{|c|c|c|c|c|c|c|}
\hline \multirow{2}{*}{ Variable } & \multicolumn{3}{|c|}{ Female } & \multicolumn{3}{|r|}{ Male } \\
\hline & $\mathbf{n}$ & Mean & SD & $\mathrm{n}$ & Mean & SD \\
\hline \multirow[t]{2}{*}{ Age } & 391 & 72.46 & 6.24 & 207 & 72.00 & 6.35 \\
\hline & $\mathrm{n}$ & $\%$ & $\%(95 \% \mathrm{Cl})$ Sarcopenia & n & $\%$ & $\%(95 \% \mathrm{Cl})$ Sarcopenia \\
\hline \multicolumn{7}{|l|}{ Educational level (in years) } \\
\hline No formal education & 26 & 6.21 & $8.93(2.51-26.73)$ & 14 & 5.24 & $38.31(15.82-67.45)$ \\
\hline 1 to 4 & 155 & 39.19 & $17.08(11.34-25.13)$ & 60 & 24.51 & $31.87(18.63-49.14)$ \\
\hline 5 to 8 & 72 & 18.36 & $14.19(5.39-32.33)$ & 34 & 20.24 & $31.31(16.17-51.71)$ \\
\hline 9 to 11 & 70 & 18.50 & $19.26(8.33-38.72)$ & 24 & 16.92 & $38.24(17.83-63.72)$ \\
\hline 12 or more & 67 & 17.74 & $20.13(10.46-35.11)$ & 75 & 33.09 & $18.66(9.81-33.00)$ \\
\hline \multicolumn{7}{|l|}{ Alcohol consumption (598) } \\
\hline No & 270 & 69.00 & $20.91(14.73-28.94)$ & 76 & 33.72 & $30.89(20.13-44.32)$ \\
\hline Moderate & 97 & 24.39 & $9.34(4.95-17.11)$ & 64 & 29.24 & $22.26(12.01-37.73)$ \\
\hline High & 24 & 6.61 & $4.32(0.87-18.51)$ & 67 & 37.14 & $32.00(18.32-49.69)$ \\
\hline \multicolumn{7}{|l|}{ Smoking habit } \\
\hline Never & 300 & 74.70 & $14.44(9.53-21.39)$ & 75 & 31.00 & $27.92(17.23-41.85)$ \\
\hline Former smoker and quit & 68 & 19.74 & $16.51(7.02-34.33)$ & 111 & 58.36 & $27.56(18.24-39.53)$ \\
\hline Currently smoking & 23 & 5.66 & $52.86(28.33-76.11)$ & 21 & 10.64 & $38.20(16.53-65.90)$ \\
\hline \multicolumn{7}{|l|}{ Physical activity } \\
\hline Insufficiently active & 192 & 48.50 & $22.33(15.44-31.12)$ & 64 & 27.30 & $37.60(22.20-56.02)$ \\
\hline Physically active & 199 & 51.50 & $12.00(7.35-19.23)$ & 143 & 72.70 & $25.49(17.12-36.18)$ \\
\hline \multicolumn{7}{|c|}{ Dependency for activities of daily living } \\
\hline No & 276 & 70.36 & $19.71(13.52-27.73)$ & 167 & 82.10 & $27.90(19.61-38.06)$ \\
\hline Yes & 115 & 29.64 & $10.57(6.01-17.99)$ & 37 & 17.90 & $33.22(19.21-50.95)$ \\
\hline \multicolumn{7}{|l|}{ Falls (last year) } \\
\hline No & 260 & 66.13 & $15.70(10.81-22.22)$ & 160 & 76.18 & $28.42(20.59-37.82)$ \\
\hline Yes & 131 & 33.87 & $19.64(11.91-30.37)$ & 47 & 23.82 & $30.11(16.32-48.85)$ \\
\hline \multicolumn{7}{|c|}{ Osteopenia/osteoporosis - T-score whole body } \\
\hline No & 159 & 41.37 & $2.50(1.13-5.42)$ & 195 & 95.10 & $27.01(19.53-69.69)$ \\
\hline Yes & 231 & 58.63 & $26.82(20.45-34.45)$ & 12 & 4.89 & $63.54(30.42-87.43)$ \\
\hline \multicolumn{7}{|c|}{ Osteopenia/osteoporosis — Lumbar Spine } \\
\hline No & 128 & 31.94 & $2.47(0.89-6.63)$ & 141 & 71.80 & $23.52(16.03-33.34)$ \\
\hline Yes & 262 & 68.06 & $23.43(17.42-30.77)$ & 66 & 28.10 & $42.34(29.51-56.22)$ \\
\hline \multicolumn{7}{|c|}{ Osteopenia/osteoporosis - Femoral Neck } \\
\hline No & 110 & 29.40 & $3.52(1.53-7.99)$ & 75 & 39.08 & $12.94(7.03-22.74)$ \\
\hline Yes & 280 & 70.60 & $22.23(16.12-29.93)$ & 132 & 60.92 & $39.05(29.49-49.41)$ \\
\hline \multicolumn{7}{|l|}{ Vitamin D } \\
\hline Normal & 101 & 30.49 & $16.33(9.1-27.62)$ & 93 & 43.43 & $26.32(17.01-38.44)$ \\
\hline Hypovitaminosis D & 271 & 69.51 & $18.02(12.61-24.89)$ & 106 & 56.57 & $30.75(21.23-42.13)$ \\
\hline \multicolumn{7}{|l|}{ Seasons } \\
\hline Spring & 55 & 15.72 & $19.63(7.69-41.48)$ & 29 & 18.05 & $34.12(15.71-58.99)$ \\
\hline Summer & 44 & 9.40 & $7.22(2.74-17.92)$ & 19 & 9.55 & $27.87(12.53-51.07)$ \\
\hline Autumn & 178 & 52.60 & $20.29(13.12-29.86)$ & 97 & 46.39 & $28.18(18.43-40.70)$ \\
\hline Winter & 95 & 22.28 & $13.66(7.74-23.45)$ & 54 & 26.01 & $26.49(15.61-41.42)$ \\
\hline
\end{tabular}

SD: standard deviation; 95\%Cl: 95\% confidence interval. 
Table 2. Crude and adjusted analysis for osteopenia/osteoporosis associated with sarcopenia in women.

\begin{tabular}{|c|c|c|c|c|}
\multirow{2}{*}{ Variables } & \multicolumn{5}{|c}{ Female } & Model 2 & Model 3 \\
\cline { 2 - 5 } & Crude Analysis & Model 1 & OR $(95 \% \mathrm{Cl})$ & OR $(95 \% \mathrm{Cl})$ \\
\cline { 2 - 5 } & OR $(95 \% \mathrm{Cl})$ & OR $(95 \% \mathrm{Cl})$ &
\end{tabular}

Osteopenia/osteoporosis - T-score whole body

\begin{tabular}{l|c|c|c|c}
\hline No & 1 & 1 & 1 & 1 \\
\hline Yes & $14.51(6.05-34.79)$ & $14.99(5.93-37.92)$ & $15.06(5.11-44.35)$ & $15.70(5.22-47.21)$ \\
\hline
\end{tabular}

Osteopenia/osteoporosis - Lumbar Spine

\begin{tabular}{l|c|c|c|c}
\hline No & 1 & 1 & 1 & 1 \\
\hline Yes & $12.00(4.11-35.07)$ & $13.27(4.34-40.52)$ & $11.32(3.50-36.64)$ & $11.32(3.43-37.29)$ \\
\hline
\end{tabular}

Osteopenia/osteoporosis - Femoral Neck

\begin{tabular}{l|c|c|c|c}
\hline No & 1 & 1 & 1 & 1 \\
\hline Yes & $3.00(1.82-4.95)$ & $3.34(1.91-5.83)$ & $2.87(1.59-5.18)$ & $5.44(1.74-16.94)$ \\
\hline Vitamin D & 1 & 1 & 1 & 1 \\
\hline Normal & $1.12(0.53-2.36)$ & $1.12(0.51-2.46)^{*}$ & $0.98(0.46-2.08)^{* *}$ & $0.75(0.35-1.63)^{* * *}$ \\
\hline Hypovitaminosis &
\end{tabular}

OR: Odds Ratio; 95\%Cl: 95\% confidence interval; Model 1: Adjusted for age and schooling; Model 2: Adjusted for age, schooling, smoking, alcohol consumption, physical activity, falls, and dependency for activities of daily living (ADL dependency); Model 3: Adjusted for age, schooling, smoking, alcohol consumption, physical activity, falls, ADL dependency, vitamin D, and season; *adjusted for age, schooling and season; **adjusted for age, schooling, smoking, alcohol consumption, physical activity, falls, ADL dependency, and season; ${ }^{* * *}$ adjusted for age, schooling, smoking, alcohol consumption, physical activity, falls, ADL dependency, season, T-score whole body, T-score BMD lumbar spine, and T-score BMD femoral neck.

Table 3. Crude and adjusted analysis for osteopenia/osteoporosis associated with sarcopenia in men.

\begin{tabular}{|c|c|c|c|c|}
\multirow{2}{*}{ Variables } & \multicolumn{5}{|c|}{ Male } \\
\cline { 2 - 6 } & Crude Analysis & Model 1 & Model 2 & Model 3 \\
\cline { 2 - 6 } & OR $(95 \% \mathrm{Cl})$ & OR $(95 \% \mathrm{Cl})$ & OR $(95 \% \mathrm{Cl})$ & OR $(95 \% \mathrm{Cl})$ \\
\hline
\end{tabular}

Osteopenia/osteoporosis T-score whole body

\begin{tabular}{l|c|c|c|c}
\hline No & 1 & 1 & 1 & 1 \\
\hline Yes & $4.70(1.09-20.27)$ & $3.49(0.71-17.09)$ & $3.94(0.78-19.86)$ & $4.24(0.91-19.57)$ \\
\hline
\end{tabular}

Osteopenia/osteoporosis Lumbar Spine

\begin{tabular}{l|c|c|c|c}
\hline No & 1 & 1 & 1 & 1 \\
\hline Yes & $2.38(1.22-4.64)$ & $2.25(1.07-4.72)$ & $2.27(1.05-4.89)$ & $2.49(1.14-5.43)$ \\
\hline
\end{tabular}

Osteopenia/osteoporosis Femoral Neck

\begin{tabular}{l|c|c|c|c}
\hline No & 1 & 1 & 1 & 1 \\
\hline Yes & $4.77(2.51-9.06)$ & $4.64(2.39-9.04)$ & $5.31(2.44-11.58)$ & $5.11(2.11-12.35)$ \\
\hline Vitamin D & 1 & 1 & 1 & 1 \\
\hline Normal & $1.23(0.63-2.42)$ & $1.19(0.59-2.40)^{*}$ & $1.05(0.50-2.23)^{* *}$ & $1.02(0.48-2.19)^{* * *}$ \\
\hline Hypovitaminosis & \multicolumn{5}{|l|}{} \\
\hline
\end{tabular}

OR: Odds Ratio; 95\%Cl: 95\% confidence interval; Model 1: adjusted for age and schooling; Model 2: adjusted for age, schooling, smoking, alcohol consumption, physical activity, falls, and dependency for activities of daily living (ADL dependency); Model 3: adjusted for age, schooling, smoking, alcohol consumption, physical activity, falls, ADL dependency, vitamin D, and season; *adjusted for age, schooling, and season; **adjusted for age, schooling, smoking, alcohol consumption, physical activity, falls, ADL dependency, and season; ${ }^{* * *}$ adjusted for age, schooling, smoking, alcohol consumption, physical activity, falls, ADL dependency, season, T-score whole body, T-score BMD. 
The results of the present study suggest that osteopenia/ osteoporosis can be considered an indicator of risk for sarcopenia among older adults with the same characteristics as the present sample. Health professionals, including those working in primary health care, can address pateints' muscular health based on information on bone density. They can reinforce the importance of strategies capable of maintaining and/or increasing muscle mass, muscle strength, and balance, to reduce the risk of falls, fractures, functional disability, and death. ${ }^{9}$

Our results showed no association between osteopenia/osteoporosis and sarcopenia; after adjustment for vitamin $\mathrm{D}$. This finding coincides, in part, with a recent meta-analysis of 12 observational studies with adults and older adults. ${ }^{28}$ Luo et al..$^{28}$ showed a significant association between blood $25(\mathrm{OH}) \mathrm{D}$ concentrations and sarcopenia. However, in contrast with our study, the studies included in the meta-analysis assessed vitamin $\mathrm{D}$ as a continuous variable or using a cutoff of $20 \mathrm{ng} / \mathrm{mL} .{ }^{28}$ It is possible that the cutoff value for vitamin $\mathrm{D}$ used in the present study was high. There is an extensive discussion on the most appropriate cutoff point for vitamin $\mathrm{D},{ }^{29}$ and we chose those recommended for the Brazilian population, where the focus is to keep blood levels above $30 \mathrm{ng} / \mathrm{mL}$ in the older adult population. ${ }^{21}$

Among the limitations of the study, we can cite the cross-sectional design, which makes it impossible to establish causal relationships between the exposures and the outcome. Another limitation concerns the losses occurred during the tests, which may lead to selection bias, since the older adults who attended at this stage had better health status than those who refused. Also, some minerals and hormones ${ }^{30}$ that are important for analysis of osteopenia/osteoporosis were not evaluated in this study, which could affect the results. Additionally, indicators of muscle strength and motor performance were not considered in the definition of sarcopenia, due to unavailability of data. Another possible limitation is the decision to combine osteopenia and osteoporosis in a single variable, which was because of the low number of individuals with osteoporosis. The Brazilian Society of Endocrinology and Metabolism definition is based on recommendations in which the minimum cut-off point for "optimal" vitamin D status is $30 \mathrm{ng} / \mathrm{ml}$ and this is the same cutoff point used by the Endocrine Society and the American Geriatric Society, but the Brazilian Society of Endocrinology and Metabolism does not classify vitamin $\mathrm{D}$ below these levels, which may be a limitation of our study.

This study highlights performance of standardized procedures and examinations, especially with relation to body composition and bone densitometry, as well as administration of questionnaires with validated scales. It is worth emphasizing that sarcopenia should be investigated using the gold standard established in the literature.
We reiterate the need for longitudinal studies and interventions to better investigate the relationship between increased $\mathrm{BMD}$ and increased muscle mass, and its influence on reducing the risk of developing sarcopenia in the older adult population.

The combination of sarcopenia and osteopenia/osteoporosis can have social and economic impacts due to complications involving the health of the affected population. The consequences of these diseases favor development of disabilities, depression, and risk of fragility fracture, in addition to increasing rates of hospitalization and mortality, thus having a significant impact on public health services.

The results also show the importance of studying these characteristics in the older adult population, since they can contribute to implementation of healthcare actions capable of preventing deterioration, early diagnosis of at-risk individuals, and even to treatment and rehabilitation for those affected.

\section{CONCLUSION}

The results of this study show that osteopenia/osteoporosis was associated with sarcopenia, in both sexes, except for whole body osteopenia/osteoporosis in men. These results suggest that preventive strategies are needed to reduce/decelerate bone loss among older adults and to prevent loss of muscle mass and ameliorate its complications for the health of this population.

\section{CONFLICTS OF INTEREST}

The authors declare no conflicts of interest.

\section{FUNDING}

This work was supported by Conselho Nacional de Desenvolvimento Científico e Tecnológico (CNPq), grant number 475.904/2013-3.

\section{AUTHORS' CONTRIBUTION}

SCC: study concept and design, analysis and interpretation of data, drafting of the manuscript, revision and approval of the final version for publication and all aspects pertaining to the entire article's accuracy and integrity. LMO: study concept and design, analysis and interpretation of data, drafting of the manuscript, revision and approval of the final version for publication and all aspects pertaining to the entire article's accuracy and integrity. LPM: study concept and design, analysis and interpretation of data, drafting of the manuscript, revision and approval of the final version for 
publication and all aspects pertaining to the entire article's accuracy and integrity. THF: analysis and interpretation of data, drafting of the manuscript, revision and approval of the final version for publication and all aspects pertaining to the entire article's accuracy and integrity. GC: analysis and interpretation of data, drafting of the manuscript, revision and approval of the final version for publication and all aspects pertaining to the entire article's accuracy and integrity.
ARB: study concept and design, analysis and interpretation of data, drafting of the manuscript, revision and approval of the final version for publication and all aspects pertaining to the entire article's accuracy and integrity. EO: study concept and design, analysis and interpretation of data, drafting of the manuscript, revision and approval of the final version for publication and all aspects pertaining to the entire article's accuracy and integrity.

\section{REFERENCES}

1. Reid KF, Pasha E, Doros G, Clark DJ, Patten C, Phillips EM, et al. Longitudinal decline of lower extremity muscle power in healthy and mobility-limited older adults: influence of muscle mass, strength, composition, neuromuscular activation and single fiber contractile properties. Eur J Appl Physiol. 2014;114(1):29-39. https://doi.org/10.1007/s00421-013-2728-2

2. Reinders I, Visser M, Schaap L. Body weight and body composition in old age and their relationship with frailty. Curr Opin Clin Nutr Metab Care. 2017;20(1):11-5. https://doi.org/10.1097/mco.0000000000000332

3. Di Monaco M, Vallero F, Di Monaco R, Tappero R. Prevalence of sarcopenia and its association with osteoporosis in 313 older women following a hip fracture. Arch Gerontol Geriatr. 2011;52(1):71-4. https://doi.org/10.1016/j.archger.2010.02.002

4. Cederholm T, Cruz-Jentoft AJ, Maggi S. Sarcopenia and Fragility Fractures. Eur J Phys Rehabil Med. 2013;49(1):111-7.

5. Baumgartner RN, Stauber PM, McHugh D, Koehler KM, Garry PJ. Cross-sectional Age Differences in Body Composition in Persons $60+$ Years of Age. Journals Gerontol Ser A Biol Sci Med Sci. 1995;50A(6):M307-16. https://doi.org/10.1093/gerona/50A.6.M307

6. Melton LJ. Adverse Outcomes of Osteoporotic Fractures in the General Population. J Bone Miner Res. 2003;18(6):1139-41. https:// doi.org/10.1359/jbmr.2003.18.6.1139

7. Baumgartner RN, Koehler KM, Gallagher D, Romero L, Heymsfield SB, Ross RR, et al. Epidemiology of sarcopenia among the elderly in New Mexico. Am J Epidemiol. 1998;147(8):755-63. https://doi. org/10.1093/oxfordjournals.aje.a009520

8. Edwards MH, Dennison EM, Aihie Sayer A, Fielding R, Cooper C. Osteoporosis and sarcopenia in older age. Bone. 2015;80:126-30. https://doi.org/10.1016\%2Fj.bone.2015.04.016

9. Oliveira A, Vaz C. The role of sarcopenia in the risk of osteoporotic hip fracture. Clin Rheumatol. 2015;34(10):1673-80. https://doi. org/10.1007/s10067-015-2943-9

10. Kaji H. Interaction between Muscle and Bone. J Bone Metab. 2014;21(1):29-40. https://doi.org/10.11005\%2Fjbm.2014.21.1.29

11. Cruz-Jentoft AJ, Baeyens JP, Bauer JM, Boirie Y, Cederholm T, Landi F, et al. Sarcopenia: European consensus on definition and diagnosis: Report of the European Working Group on Sarcopenia in Older People. Age Ageing. 2010;39(4):412-23. https://doi.org/10.1093/ageing/afq034

12. Moraes LFS, Silva EN da, Silva DAS, Paula AP de. Expenditures on the treatment of osteoporosis in the elderly in Brazil (2008 - 2010): analysis of associated factors. Rev Bras Epidemiol. 2014;17(3):71934. https://doi.org/10.1590/1809-4503201400030012

13. Janssen I, Shepard DS, Katzmarzyk PT, Roubenoff R. The Healthcare Costs of Sarcopenia in the United States. J Am Geriatr Soc. 2004;52(1):80-5. https://doi.org/10.1111/j.1532-5415.2004.52014.x

14. Roubenoff R. Sarcopenic obesity: The confluence of two epidemics. Obes Res. 2004;12(6):887-8. https://doi.org/10.1038/oby.2004.107

15. Li G, Zhang L, Wang D, AIQudsy L, Jiang JX, Xu H, et al. Muscle-bone crosstalk and potential therapies for sarco-osteoporosis. J Cell Biochem. 2019;120(9):14262-73. https://doi.org/10.1002/jcb.28946

16. Yoshimura N, Muraki S, Oka H, lidaka T, Kodama R, Kawaguchi H, et al. Is osteoporosis a predictor for future sarcopenia or vice versa? Four-year observations between the second and third ROAD study surveys. Osteoporos Int. 2017;28(1):189-99. https://doi.org/10.1007/s00198-016-3823-0
17. Avin KG, Bloomfield SA, Gross TS, Warden SJ. Biomechanical Aspects of the Muscle-Bone Interaction. Curr Osteoporos Rep. 2015;13(1):1-8. https://doi.org/10.1007\%2Fs1 1914-014-0244-x

18. Confortin SC, Schneider IJC, Antes DL, Cembranel F, Ono LM, Marques LP, et al. Condições de vida e saúde de idosos: resultados do estudo de coorte EpiFloripa Idoso. Epidemiol Serv Saúde. 2017:26(2):30517. https://doi.org/10.5123/s1679-49742017000200008

19. Kanis JA, Melton LJ, Christiansen C, Johnston CC, Khaltaev N. The diagnosis of osteoporosis. J Bone Miner Res. 1994;9(8):1137-41. https://doi.org/10.1002/jbmr.5650090802

20. Pereira FB, Leite AF, Paula AP de. Relationship between pre-sarcopenia, sarcopenia and bone mineral density in elderly men. Arch Endocrino Metab. 2015;59(1):59-65. https://doi.org/10.1590/2359-399700000001 1

21. Maeda SS, Borba VZC, Camargo MBR, Silva DMW, Borges JLC Bandeira F, et al. Recomendações da Sociedade Brasileira de Endocrinologia e Metabologia (SBEM) para o diagnóstico e tratamento da hipovitaminose D. Arq Bras Endocrinol Metabol. 2014;58(5):411-33. https://doi.org/10.1590/0004-2730000003388

22. Craig CL, Marshall AL, Sjöström M, Bauman AE, Booth ML, Ainsworth $\mathrm{BE}$, et al. International physical activity questionnaire: 12-Country reliability and validity. Med Sci Sports Exerc. 2003;35(8):1381-95. https://doi.org/10.1249/01.mss.0000078924.61453.fb

23. Rosa TE da C, Benício MHD, Latorre M do RD de O, Ramos LR. Fatores determinantes da capacidade funcional entre idosos. Rev Saude Publica. 2003;37(1):40-8. https://doi.org/10.1590/S0034-89102003000100008

24. Bijlsma AY, Meskers MCG, Molendijk M, Westendorp RGJ, Sipilä S, Stenroth L, et al. Diagnostic measures for sarcopenia and bone mineral density. Osteoporos Int. 2013;24(10):2681-91. https://doi. org/10.1007/s00198-013-2376-8

25. Pongchaiyakul C, Limpawattana P, Kotruchin P, Rajatanavin R Prevalence of sarcopenia and associated factors among Thai population. J Bone Miner Metab. 2013;31(3):346-50. https://doi. org/10.1007/s00774-013-0422-4

26. Figueiredo CP, Domiciano DS, Lopes JB, Caparbo VF, Scazufca $\mathrm{M}$, Bonfá $\mathrm{E}$, et al. Prevalence of sarcopenia and associated risk factors by two diagnostic criteria in community-dwelling older men: the São Paulo Ageing \& Health Study (SPAH). Osteoporos Int. 2014;25(2):589-96. https://doi.org/10.1007/s00198-013-2455-x

27. Lang TF. The Bone-Muscle Relationship in Men and Women.J Osteoporos 2011;2011:702735. https://doi.org/10.4061/2011/702735

28. Luo J, Quan Z, Lin S, Cui L. The association between blood concentration of 25- hydroxyvitamin D and sarcopenia: A metaanalysis. Asia Pac J Clin Nutr. 2018;27(6):1258-70. https://doi. org/10.6133/apjcn.201811_27(6).0013

29. Giustina A, Adler RA, Binkley N, Bollerslev J, Bouillon R, DawsonHughes B, et al. Consensus statement from 2nd International Conference on Controversies in Vitamin D. Rev Endocr Metab Disord. 2020;21(1):89-116. https://doi.org/10.1007/s11154-019-09532-w

30. El Maataoui A, Benghabrite A, El Maghraoui A, Chabraoui L, Ouzzif $Z$. Relationship between sex hormone levels, bone mineral density and bone turnover markers in healthy moroccan men: $A$ cross-sectional study. Pan Afr Med J. 2015;22:206. https://doi. org/10.11604\%2Fpamj.2015.22.206.6066 